\title{
Cardiac tamponade - unusual clinical manifestation of undiagnosed malignant neoplasm
}

\author{
B. PEREK ${ }^{1, \star}$, I. TOMASZEWSKA $^{2}$, S. STEFANIAK ${ }^{1}$, I. KATYNSKA ${ }^{1}$, M. JEMIELITY ${ }^{1}$
}

${ }^{1}$ Department of Cardiac Surgery and Transplantology, Poznan University of Medical Sciences, Poznan, Poland; ${ }^{2}$ Ist Department of Cardiology, Poznan University of Medical Sciences, Poznan, Poland

*Correspondence: bperek@yahoo.com

Received November 21, 2015 / Accepted March 2, 2016

\begin{abstract}
Cardiac tamponade may be the first or predominant symptom of some pathologies but its etiology is not uncommonly unknown on admission to hospital. The purpose of this study was to evaluate the predominant causes of cardiac tamponade in previously healthy patients treated emergently in a single cardiac surgical center. The study involved 81 patients with the mean age of $58.1 \pm 16.0$ years who underwent emergent subxyphoid pericardiotomy due to cardiac tamponade. Pericardial effusion was analyzed macro- and microscopically. Examinations done in the cardiac surgical department revealed pericarditis secondary to infection $(n=17)$ or autoimmunologic processes $(n=2)$ and malignancy in 18 patients (predominantly of the lungs $(n=11)$ ). Pericardial effusion obtained from patients with viral and autoimmunologic-induced pericarditis was strawcolor and odorless while with bacterial infections dark yellow, iridescent and usually malodorous. Additional workup in the regional hospitals enabled to reveal malignant tumors in 29 patients, leukemia or lymphoma in 5 subjects. In all but one of the neoplastic cases, pericardial fluid was turbid and dark red or plummy. In 10 patients etiology of tamponade remained unknown. In conclusion, cardiac tamponade in previously healthy patients may be occasionally the predominant symptom of cancer, especially of the lungs. Macroscopic intraoperative appearance of pericardial fluid may be helpful in identification of causative condition of cardiac tamponade.
\end{abstract}

Key words: cardiac tamponade, pathogenesis, malignant neoplasm, diagnosis

Excessive pericardial effusion accompanied by increased pericardial pressure leading to cardiac tamponade is a lifethreatening condition that requires emergent intervention [1]. Due to impaired cardiac function and compromised hemodynamics in the majority of subjects with symptomatic cardiac tamponade, there is usually not enough time to perform a series of diagnostic examinations to reveal a real cause of this entity. Thus, some cases referred to cardiac surgical centers with cardiac tamponade are of unknown etiology on admission $[2,3]$. Not uncommonly a variety of additional

\footnotetext{
Abbreviations: ALT - alanine aminotrasferase; AST - aspartate aminotrasferase; BMI - body mass index; CK-MB - creatine kinase MB isoenzyme; CMV - Cytmegalovirus; CT - computed tomography; EBV Ebstein-Barr virus; GFR - glomerular filtration rate; HDL-C - high-density lipoprotein cholesterol; LDL-C - low-density lipoprotein cholesterol; MRI magnetic resonance imaging; PE - pericardial effusion; PLT - platelets count; RBC - red blood cells count; RV - right ventricle; TC - total cholesterol; TG - triglycerides; WBC - white blood cells count
}

imaging modalities performed after surgical intervention enable to establish the final diagnosis $[4,5]$.

The aim of this study was to evaluate the predominant causes of cardiac tamponade in previously healthy patients admitted emergently to a single cardiac surgical center.

\section{Patients and methods}

Patients. Between January 2006 and December 2014, 172 patients (103 males and 69 females) were treated emergently due to symptomatic primary cardiac tamponade. On admission, etiology of pericardial effusion was unknown in 81 patients $(47.1 \%)$ and these patients comprised the group of interest (Figure 1). Patients with asymptomatic pericardial effusion and secondary to previous cardiologic or/and cardiac surgical procedures ('secondary tamponade') and terminally ill cancer patients who usually undergo needle pericardiocentesis were not included in this study. Patients 


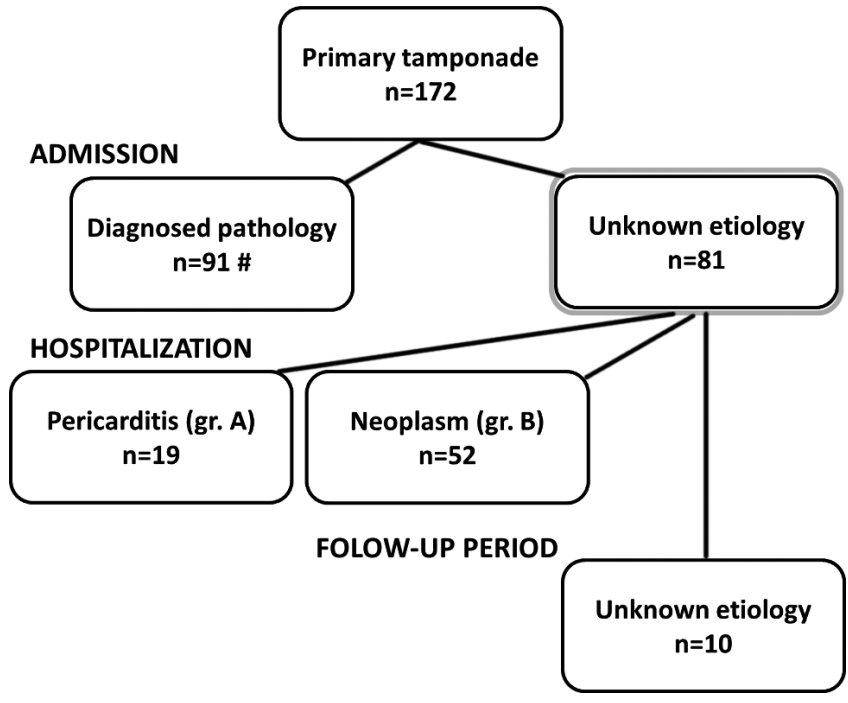

Figure 1. Patients selection. Patients with cardiac tamponade secondary to recent cardiac surgical operations or interventional cardiologic procedures were not included. \# Other causes: diagnosed previously neoplasm $(\mathbf{n}=63$; $36.6 \%)$, pericarditis $(n=14 ; 8.1 \%)$, end-stage heart failure $(n=6 ; 3.5 \%)$, myxedema $(n=5 ; 2.9 \%)$ and heart failure $(n=3 ; 1.7 \%)$.

were retrospectively divided into three following subgroups with respect to an underlying pathology that led to pericardial effusion and eventually to cardiac tamponade such as group A (pericarditis; $n=19$ ), group $B$ (neoplasm; $n=52$ ), group $\mathrm{C}$ (unknown etiology; $\mathrm{n}=10$ ).

Admission. All patients were treated emergently soon after admission to the cardiac surgical department. Blood samples for the routine laboratory analyzes were taken. Transthoracic echocardiography was mandatory examination to confirm a diagnosis of cardiac tamponade (Figure 2). Following obligatory preparations, patients were immediately transferred to the operating theater.

Surgery. All patients underwent subxyphoid pericardiotomy under general anesthesia. Skin incision 4 to $6-\mathrm{cm}$ in length was done, subcutaneous tissues and xyphoid process were dissected free. Pericardium was identified and then a hole in it was performed. Pericardial effusion was evacuated intraoperatively. If necessary, the pleural cavities were also drained. In all cases, the pericardial effusion was analyzed macro- and microscopically (general, biochemical, microbiological and cytological examinations).

Postoperative period. After surgery, imaging examinations were usually performed, predominantly computed tomography (CT), to find the causative conditions. The majority of patients were discharged from our department on the day following removal of the chest drains and were transferred to the regional hospitals where further workup was done. Afterwards, all patients underwent systematic follow-up in a outpatient clinic and echocardiographic examination at the end of the follow-up period was performed.

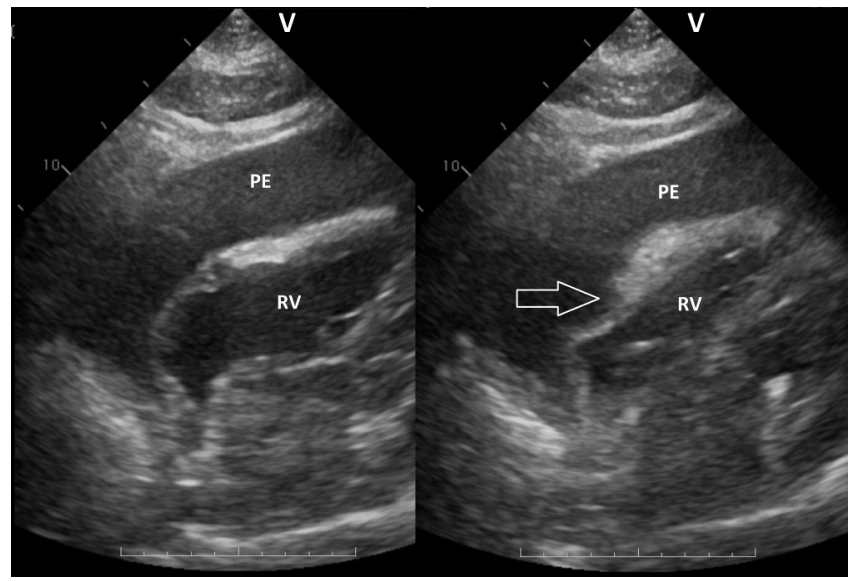

Figure 2. Typical echocardiographic appearance of cardiac tamponade. Note! Huge amount (more than $3.5 \mathrm{~cm}$ in front of the right ventricle (RV)) of the pericardial effusion (PE) of unknown etiology compresses RV.

Statistical analysis. Continuous variables were checked for normality using the Shapiro-Wilk W test. Normally distributed continuous data are presented as the means with standard deviations (sd) while the others (e.g., follow-up period, pericardial effusion volume) are expressed as the medians with minimal and maximal values. Categorical variables are presented as the numbers with percentages. The Kruskal-Wallis ANOVA test for comparison of the multiple independent samples was used. If the $\mathrm{P}$ value of this test was below 0.05 , multiple comparisons of mean ranks was performed to reveal any significant differences between particular subgroups. Then $\mathrm{P}$ values were corrected using Bonferroni adjustment method by simple multiplication of observed $\mathrm{P}$ value by the number of comparisons made. Eventually, the corrected $P$ values below 0.05 were considered as significant. Statistical analysis was carried out in Statistica 9.0 for Windows (Tulsa, OH, USA).

\section{Results}

The examined group of 81 patients consisted of 59 males and 22 females with the mean age of $58.1 \pm 16.0$ years (ranging from 20 to 86 years).

The possible underlying pathology that led to the pericardial effusion was revealed during hospitalization in our department in 37 cases (see Table 1). Cardiac tamponade was considered as a result of pericarditis related to acute infections or to autoimmunologic processes in 19 individuals. Moreover, in 18 patients malignant neoplasms were found. They were diagnosed exclusively in CT $(n=10)$ or only in cytological examination of the pericardial effusion $(n=5)$ or in both of them $(n=3)$. Thus, in 8 patients a presence of the neoplastic cells was the first sign of any malignancy. In 
four of them lung adenocarcinoma, in three non-Hodgkin lymphoma and in one papillary thyroid carcinoma cells were found. Identification of neoplastic cells in the pericardial fluid determined to diagnose stage IV of malignancy according to TNM classification.

Forty four patients were discharged from our department without established diagnosis. However, they were referred either to the other departments (mainly hematological) or to the regional hospitals where additional studies were performed. In the majority of them $(34 / 44 ; 77.3 \%)$ further examinations enabled to establish the final diagnosis (see Table 1). In one case, re-accumulation of pericardial effusion resulted in re-admission to our center one month after the primary intervention and at that time lung cancer was diagnosed. The mean period to establish the final diagnosis of neoplasm was 3 months (1, 5 months). Unfortunately, in a vast majority of neoplastic cases malignant process was disseminated (stage IV disease). However, lower stages of neoplasm were noted in patients with lung cancer or chronic leukemia, both diagnosed after discharge from cardiac surgical department. Later diagnosis of lung cancer referred to more cases in stage II and less in stage IV of disease as compared to subjects with early identification of lung tumors. Other details regarding staging of neoplasms are outlined in the Table 1.

In 10 patients we were not able to find a causative condition. However, they did not need any further medical intervention throughout follow-up period (median 60 months) and at the end of it no pericardial effusion was noted in transthoracic echoacrdiography.

Comparing demographics and results of the analyzes of preoperative blood samples some differences between the subgroups were found. First of all, patients with diagnosed lymphoma or leukemia were significantly younger $(28.6$ \pm 8.7 years; ranged 20 to 43$)$ than the remainders (60.6 \pm 13.2 years; 35 to 86$)(\mathrm{p}<0.001)$. Patients with neoplastic cardiac tamponade had lower body mass index (BMI), less erythrocyte counts and decreased concentrations of total cholesterol and low-density lipoprotein cholesterol (LDL-C) as well as lower glomerular filtration rate (GFR) comparing to the others. Contrary to them, infectioninduced cardiac tamponade patients had significantly higher leukocyte and platelet counts as well as increased fibrinogen concentration than neoplastic patients. The detailed results of statistical analysis of these variables are summarized in the Table 2.

Volume of pericardial effusion drained intraoperatively was markedly lower among group C patients $(440 \mathrm{ml}(300$, $720 \mathrm{ml})$ ) as compared to either group A (750 $\mathrm{ml}(450,2000$ $\mathrm{ml}) ; \mathrm{p}=.0208)$ or group $\mathrm{B}(680 \mathrm{ml}(350,1400 \mathrm{ml}) ; \mathrm{p}=.0277)$. Additionally, in patients with viral and autoimmunologic-induced pericarditis, pericardial fluid was usually $(12 / 13 ; 92.3 \%)$ clear, straw-color and odorless while with bacterial infections dark yellow, iridescent and commonly malodorous. In all but one of neoplastic patients, fluid evacuated from the pericardium
Table 1. Underlying pathologies

\begin{tabular}{|c|c|c|}
\hline $\mathrm{N}=81$ & Diagnosis & Number* \\
\hline In our department & Pericarditis & 19 \\
\hline \multirow[t]{11}{*}{$\mathrm{N}=37$} & viral (CMV, EBV) & 11 \\
\hline & $\begin{array}{l}\text { bacterial (staphylococcus } \\
\text { spec.) }\end{array}$ & 6 \\
\hline & tuberculosis & 2 \\
\hline & Immunological process & 2 \\
\hline & rheumatoid arthritis & 1 \\
\hline & lupus erythematosus & 1 \\
\hline & Neoplasms & 18 \\
\hline & Lung cancer & $11(\operatorname{IIIB}(\mathrm{n}=4), \operatorname{IV}(7)) \&$ \\
\hline & Heart and pericardial tumors & 3 (non applicable) \\
\hline & Non-Hodgkin lymphoma & $3(\mathrm{IV})$ \\
\hline & Thyroid gland cancer & $1(\mathrm{IV})$ \\
\hline After discharge & Solid tumors & 29 \\
\hline \multirow[t]{5}{*}{$\mathrm{N}=34$} & Lung cancer & $\begin{array}{l}25 \text { (IIB (9); IIIA (10); } \\
\text { IIIB (6))\& }\end{array}$ \\
\hline & Breast cancer & $2(\mathrm{IV})$ \\
\hline & Ovary cancer & $1(\mathrm{IV})$ \\
\hline & Pleural mesothelioma & 1 (III) \\
\hline & Leukemia $^{\mathrm{s}}$ and lymphoma & $5\left(\mathrm{II}(1)^{\S}, \mathrm{III}(2)^{\$}, \mathrm{IV}(2)\right)$ \\
\hline Unknown $^{\#}$ & & 10 \\
\hline
\end{tabular}

${ }^{*}$ staging of malignant neoplasm (according to TNM classification) and number of patients within the brackets; ${ }^{8}$ the 7 th lung cancer staging system [21]; ${ }^{\text {} R a i ~ c l a s s i f i c a t i o n ~ f o r ~ l e u k e m i a ; ~ " c a r d i a c ~ t a m p o n a d e ~ o f ~ u n k n o w n ~ e t i o l-~}$ ogy at the end of the follow-up period. Abbreviations: CMV = Cytomegalovirus; $\mathrm{EBV}=$ Ebstein-Barr virus.

was turbid and dark red or plummy. Interestingly, in all cases with pericardial effusion of unknown etiology fluid was serous and straw-color.

\section{Discussion}

First of all, it must be stressed again that our study focused exclusively on the patients with symptomatic cardiac tamponade. Only a minority of patients with pericardial effusion manifest clinically cardiac tamponade $[6,7]$. For instance, in Sagristà-Sauleda study the prevalence of cardiac tamponade was $37 \%$ among patients with large pericardial effusion [7]. However, this entity is considered as the highest degree of severity of pericardial disease $[8,9]$. It results from either large volume or rapidly accumulated fluid in the pericardial sack. Cardiac tamponade as a life-threatening condition requires emergent intervention. Thus in many patients is difficult to establish etiology of fluid accumulation in the pericardium at the time of admission to cardiologic/cardiac surgical centers and before any intervention.

Pericardial effusion in malignancy patients is rather common. However, it usually involves terminally ill subjects with established diagnosis [10]. It is estimated that even up to 15- 
Table 2. Preoperative demographics and laboratory data

\begin{tabular}{|c|c|c|c|c|}
\hline Variable & $\begin{array}{c}\text { Group A } \\
\mathrm{N}=19\end{array}$ & $\begin{array}{c}\text { Group B } \\
\mathrm{N}=52\end{array}$ & $\begin{array}{c}\text { Group C } \\
\mathrm{N}=10\end{array}$ & $\mathrm{P}$ value ${ }^{1}$ \\
\hline Age [years] & $55.1 \pm 14.7$ & $56.6 \pm 15.8$ & $60.5 \pm 14.2$ & 0.125 (NS) \\
\hline Gender $[\mathrm{M} / \mathrm{F}]$ & $14 / 5$ & $38 / 14$ & $7 / 3$ & $0.134(\mathrm{NS})$ \\
\hline Height $[\mathrm{cm}]$ & $169.3 \pm 7.8$ & $172.1 \pm 5.3$ & $175.4 \pm 7.7$ & 0.356 (NS) \\
\hline Weight $[\mathrm{kg}]$ & $90.2 \pm 14.0$ & $70.5 \pm 14.1^{*}$ & $91.4 \pm 5.4$ & $<0.001$ \\
\hline BMI $\left[\mathrm{kg} / \mathrm{m}^{2}\right]$ & $30.1 \pm 2.4$ & $23.6 \pm 5.0^{*}$ & $29.8 \pm 3.0$ & $<0.001$ \\
\hline Hemoglobin $[\mathrm{mmol} / \mathrm{L}]$ & $8.23 \pm 1.04$ & $7.97 \pm 0.96$ & $8.32 \pm 0.38$ & $0.611(\mathrm{NS})$ \\
\hline $\mathrm{RBC}\left[\mathrm{x} 10^{12} / \mathrm{L}\right]$ & $4.63 \pm 0.11$ & $4.23 \pm 0.49^{8}$ & $4.88 \pm 0.24$ & 0.011 \\
\hline $\mathrm{WBC}\left[\mathrm{x} 10^{9} / \mathrm{L}\right]$ & $17.9 \pm 2.2^{s}$ & $13.1 \pm 3.0^{*}$ & $7.5 \pm 0.8$ & $<0.001$ \\
\hline $\operatorname{PLT}\left[\mathrm{x} 10^{9} / \mathrm{L}\right]$ & $476 \pm 119$ & $262 \pm 102^{\#}$ & $348 \pm 127$ & 0.005 \\
\hline Fibrinogen $[\mathrm{mg} / \mathrm{dL}]$ & $674 \pm 165$ & $422 \pm 181^{\#}$ & $533 \pm 117$ & 0.015 \\
\hline CK-MB mass $[\mu \mathrm{g} / \mathrm{L}]$ & $2.42 \pm 0.66$ & $2.48 \pm 1.10$ & $2.34 \pm 0.77$ & $0.621(\mathrm{NS})$ \\
\hline Troponin I $[\mu \mathrm{g} / \mathrm{L}]$ & $0.11 \pm 0.02$ & $0.02 \pm 0.01$ & $0.05 \pm 0.01$ & 0.176 (NS) \\
\hline $\mathrm{TC}[\mathrm{mmol} / \mathrm{L}]$ & $4.65 \pm 0.65^{@}$ & $3.77 \pm 1.13$ & $3.84 \pm 0.55$ & 0.006 \\
\hline $\mathrm{HDL}-\mathrm{C}[\mathrm{mmol} / \mathrm{L}]$ & $1.03 \pm 0.25$ & $0.85 \pm 0.26$ & $0.92 \pm 0.27$ & $0.303(\mathrm{NS})$ \\
\hline $\mathrm{LDL}-\mathrm{C}[\mathrm{mmol} / \mathrm{L}]$ & $3.13 \pm 0.60^{@}$ & $2.40 \pm 0.89$ & $2.45 \pm 0.33$ & 0.003 \\
\hline $\mathrm{TG}[\mathrm{mmol} / \mathrm{L}]$ & $1.19 \pm 0.49$ & $1.07 \pm 0.34$ & $0.98 \pm 0.09$ & 0.460 (NS) \\
\hline ALT [IU/L] & $43.8 \pm 9.4$ & $36.4 \pm 7.4$ & $35.4 \pm 4.9$ & 0.937 (NS) \\
\hline AST [IU/L] & $24.2 \pm 4.0$ & $23.6 \pm 5.7$ & $26.2 \pm 2.2$ & 0.738 (NS) \\
\hline $\mathrm{GFR}[\mathrm{mL} / \mathrm{min}]^{2}$ & $85.1 \pm 12.2$ & $65.9 \pm 11.4^{*}$ & $95.1 \pm 10.5$ & 0.008 \\
\hline
\end{tabular}

${ }^{1}$ The Kruskal-Wallis ANOVA test for comparison of the multiple independent samples with Bonferroni correction; Multiple comparisons of the mean ranks revealed following: ${ }^{\star} \mathrm{P}<.05$ group $\mathrm{B}$ vs. A or $\mathrm{C} ;{ }^{\circledR} \mathrm{P}<.05$ group $\mathrm{B}$ vs. $\mathrm{C} ;{ }^{\circledR} \mathrm{P} .<.05$ group A vs. $\mathrm{C} ;{ }^{*} \mathrm{P}<.05$ group A vs. $\mathrm{B} ;{ }^{\circledR} \mathrm{P}<.05$ group A vs. B or $\mathrm{C} ;{ }^{2} \mathrm{GFR}$ calculated according to the Cockcroft-Gault formula.

Abbreviations: $\mathrm{ALT}=$ alanine aminotransferase; $\mathrm{AST}=$ aspartate aminotraferase; $\mathrm{BMI}=$ body mass index; $\mathrm{CK}-\mathrm{MB}=$ creatine kinase $\mathrm{MB}$ isoenzyme; $\mathrm{GFR}=\mathrm{glomerular}$ fitration rate; HDL-C=high-density lipoprotein cholesterol; LDL-C=low-density lipoprotein cholesterol; PLT=platelets count; RBC=red blood cells count; $\mathrm{TC}=$ total cholesterol; $\mathrm{TG}=$ triglycerides; $\mathrm{WBC}=$ white blood cells count.

$20 \%$ of them have metastases to the pericardium via either direct cancer extension or lymphatic and hematogeous routs [11]. In our study, although the majority of patents had disseminated disease and were found in stage IV according to TNM classification they were in relatively good clinical shape in the terms of metabolic status and internal organ performance. We are aware that our group of patients represents very small percentage of individuals with cancer-induced pericardial effusion. The most advanced stages of neoplasms were observed if atypical cells were found in pericardial fluid or final diagnosis could be established soon after surgery during in-hospital stay. It applied particularly to lung cancer cases. More than $60 \%$ among early identified lung cancer subjects were in stage IV disease while nobody in subgroup with late diagnosis.

In our group the vast majority had lung cancer, mediastinal tumors or leukemia/lymphoma. These findings are consistent with the results of the previous reports $[6,12,13]$. Lung and breast cancer cases together with hematological malignancies were reported to cause approximately 70-75\% neoplastic accumulation of pericardial fluid [12]. The only difference is a relatively low prevalence of breast cancer patients in our group. Breast cancer-induced cardiac tamponade was pretty common among patients with known causative condition on admission to the cardiac surgical department. Moreover, all of them were during chemio- and radiotherapy. Thus, it is possible that local tumor extension in breast cancer women was less involved in pericardial effusion than the following mechanisms such as radiotherapy and chemiotherapy toxicity or opportunistic acute infections promoted by immunosuppressive therapy [14]. The aforementioned etiologic factors are not applicable to our group since only patients with cardiac tamponade of unknown etiology were included. Although pericardial neoplastic involvement is considered as an advanced stage of cancer, in some of them primary tumors are relatively asymptomatic for a pretty long time. Sometimes, the final diagnosis is established during repeat hospitalization for fluid recurrence [15]. More interestingly, in some cases accumulation of pericardial fluid associated with malignancy may be slow [16]. This fact may explain a relatively large volume of effusion that is usually seen in neoplastic cardiac tamponade. In our group, this volume was significantly higher than in group C.

Although pericarditis, especially viral one, has been described to be the most common cause of pericardial effusion, only a small percentage of them leads to cardiac tamponade 
$[17,18]$. Inflammation usually takes at least few weeks and in a majority of cases is associated with pain, fever, fatigue and pericardial friction rub that proceeded larger volume accumulation. Thus these patients are often treated successfully with anti-inflammatory drugs and/or antibiotics if applicable while only the minority of them had to undergo invasive procedures to evacuate pericardial effusion [13]. Even in the latter clinical scenario, only few of them must be treated emergently. In our group, they account for $23 \%$ of all patients that is consistent with the previous reports.

Laboratory studies of blood samples and particularly marco- and microscopic analysis of fluid drained from the pericardium completed by imaging studies such as CT or magnetic resonance (MRI) are of paramount importance and they may indicate the possible causative condition $[13,19]$. In our study we found significant difference in the results of laboratory examinations between cancer (group B) and pericarditis patients (group A). For example, in group A patients, typical inflammatory pattern with high leukocyte and platelet counts as well as elevated fibrinogen concentration, one of many acute phase proteins, were noted. Contrary to them, neoplastic patients manifested typical findings for chronic diseases such as anemia or low total cholesterol and LDL-C concentrations. It is not difficult to presume macroscopic appearance of inflammatory pericardial effusion either viral (pale yellow) or bacterial. The different is fluid of cancer etiology. Turbid and dark red-colored should direct our search for malignant processes.

A particular group are patients whose etiology of tamponade remained undisclosed to the end of the follow-up period. It is possible that viral infection was predominant causative factor since the accumulated fluid was similar to that one drained from the pericardium of viral infection-induced cardiac tamponade (group A) but we were not able to find it. Because they were alive and remained asymptomatic at the end of follow-up lasting a few years, the underlying pathology was not likely any malignancy that unfortunately is usually associated with very poor prognosis and drastically reduced long-term survival rate, commonly to a few months [20].

Concluding, pericardial effusion leading to cardiac tamponade in previously healthy patients may be occasionally the predominant symptom of malignant neoplasm, especially of the lungs. Laboratory studies and particularly macroscopic intraoperative appearance of pericardial fluid may be helpful in identification of causative condition of cardiac tamponade.

\section{References}

[1] SPODICK DH. Current concepts: Acute cardiac tamponade. N Engl J Med 2003; 348: 684-690. http://dx.doi.org/10.1056/ NEJMra022643

[2] SOOFI MA, YOUSSEF MA. Metastatic adenocarcinoma presenting as choroidal mass and recurrent cardiac tamponade. J Coll Physicians Surg Pak 2014; 24 (Suppl 1): S5-S7.
[3] BURAZOR I, IMAZIO M, MARKEL G, ADLER Y. Malignant pericardial effusion. Cardiology 2013; 124: 224-232. http:// dx.doi.org/10.1159/000348559

[4] SCHEININ SA, SOSA-HERRERA J. Case report: cardiac tamponade resembling an acute myocardial infarction as the initial manifestation of metastatic pericardial adenocarcinoma. Methodist Debakey Cardiovasc J 2014; 10: 124-128. http://dx.doi.org/10.14797/mdcj-10-2-124

[5] BALGHiTH M, TAYLOR DA, JUGDUTT BI. Cardiac tamponade as the first manifestation of metastatic adenocarcinoma of the lung. Can J Cardiol 2000; 16: 925-927.

[6] COLOMBO A, OLSON HG, EGAN J, GARDIN JM. Etiology and prognostic implications of a large pericardial effusion in men. Clin Cardiol 1988; 11: 389-394. http://dx.doi. org/10.1002/clc.4960110606

[7] SAGRISTA-SAULEDA J, MERCE J, PERMANYER-MIRALDA G, SOLER-SOLER J. Clinical clues to the causes of large pericardial effusions. Am J Med 2000; 109: 95-101. http:// dx.doi.org/10.1016/S0002-9343(00)00459-9

[8] SAGRISTA-SAULEDA J, MERCE AS, SOLER-SOLER J. Diagnosis and management of pericardial effusion. World J Cardiol 2011; 3: 135-143. http://dx.doi.org/10.4330/wjc.v3.i5.135

[9] MERCE J, SAGRISTA-SAULEDA J, PERMANYER-MIRALDA G, EVANGELISTA A, SOLER-SOLER J. Correlation between clinical and Doppler echocardiographic findings in patients with moderate and large pericardial effusion: implications for the diagnosis of cardiac tamponade. Am Heart J 1999; 138: 759-764. http://dx.doi.org/10.1016/S00028703(99)70193-6

[10] LETONJA M, DEBELJAK A. Cardiac tamponade as the initial manifestation of pulmonary adencarcinoma. Radiol Oncol 2007; 41: 161-165. http://dx.doi.org/10.2478/v10019-007-0025-6

[11] SKHVATSABAJA LV. Secondary malignant lesions of the heart and pericardium in neoplastic disease. Oncology 1986; 43: 103-106. http://dx.doi.org/10.1159/000226344

[12] BUZAID AC, GAREWAL HS, GREENBERG BR. Managing malignant pericardial effusion. West J Med 1989; 150: 174-179.

[13] CHILES C, WOODARD PK, GUTIERREZ FR, LINK KM. Metastatic involvement of the heart and pericardium: CT and MR imaging. Radiographics 2001; 21: 439-449. http://dx.doi. org/10.1148/radiographics.21.2.g01mr15439

[14] REFAAT MM, KATZ WE. Neoplastic pericardial effusion. Clin Cardiol 2011; 34: 293-598.

[15] The Task Force on the Diagnosis and Management of Pericardial Diseases of the European Society of Cardiology. Guidelines on the Diagnosis and Management of Pericardial Disease. Eur Heart J 2004; 25: 587-610.

[16] EL-OSTA HE, YAMMINE YS, CHEHAB BM, FIELDS AS, MOORE DF JR. et al. Unexplained hemopericardium as a presenting feature of primary cardiac angiosarcoma: a case report and a review of the diagnostic dilemma. J Thorac Oncol 2008; 3: 800-802. http://dx.doi.org/10.1097/ JTO.0b013e31817c9282

[17] SILVA-CARDOSO J, MOURA B, MARTINS L, MOTAMIRANDA A, ROCHA-GONÇALVES F. et al. Pericardial involvement in human immunodeficiency virus infection. Chest 1999; 15: 418-422. http://dx.doi.org/10.1378/chest.115.2.418 
[18] PERMANYER-MIRALDA G, SAGRISTA-SAULEDA J, SOLER-SOLER J. Primary acute pericardial disease: a prospective series of 231 consecutive patients. Am J Cardiol 1985; 56: 623-630. http://dx.doi.org/10.1016/0002-9149(85)91023-9

[19] RESTREPO CS, LEMOS DF, LEMOS JA. et al. Imaging findings in cardiac tamponade with emphasis on CT. Radiographics 2007; 27: 1595-1610. http://dx.doi.org/10.1148/ rg. 276065002
[20] MINAGAWA T, MURATA Y, UCHIKAWA S, UEHARA T. Malignant pericardial tamponade in a patient with hormonerefractory prostate cancer. Int J Clin Oncol 2010; 15: 101-103. http://dx.doi.org/10.1007/s10147-009-0002-8

[21] MIRSADRAEE S, OSWAL D, ALIZADEH Y, CAULO A, VAN BEEK E JR. The 7th lung cancer TNM classification and staging system. Review of the changes and implications. World J Radiol 2012; 4: 128-134. http://dx.doi.org/10.4329/wjr.v4.i4.128 